\title{
Air to Air Energy Recovery from HVAC Systems under Different Membrane Materials
}

\author{
Rafat F. Al-Waked ${ }^{1, *}$, Mohammad S. Nasif ${ }^{2}$ \\ ${ }^{1}$ Department of Mechanical and Maintenance Engineering, German Jordanian University, Jordan \\ ${ }^{2}$ Department of Mechanical Engineering, Universiti Teknologi PETRONAS, Malaysia
}

Copyright $\odot 2019$ by authors, all rights reserved. Authors agree that this article remains permanently open access under the terms of the Creative Commons Attribution License 4.0 International License

\begin{abstract}
Membrane heat exchanger is one of the main components of green HVAC systems. Performance of a thin-membrane heat exchanger has been examined for different membrane materials. A computational fluid dynamics (CFD) approach was utilized to conduct the current study. The CFD model consisted of a single channel for hot stream and another channel for cold stream. Four membranes were investigated: $45 \mathrm{gsm}$ and $60 \mathrm{gsm}$ Kraft paper, modified cellulose acetate membrane and $\mathrm{PVA} / \mathrm{LiCl}$ blend membrane. Obtained values of thermal effectiveness at typical HVAC system conditions showed that different membrane materials produced different thermal performance values. The amount of energy recovered from the modified cellulose acetate membrane heat exchanger was the highest. Finally, heat exchanger performance is found to be very sensitive to ambient air relative humidity variation.
\end{abstract}

Keywords Membrane Heat Exchanger, ERV, CFD, Heat Transfer, Mass Transfer

\section{Introduction}

Indoor air quality of commercial buildings has become a great concern for the air conditioning industry when combined with energy efficiency. Volatile organic compounds, smoke, dust and bacteria affects the health of those people who spend more than $80 \%$ of their time indoors by causing sickness and respiratory diseases. In conventional air conditioning systems, about $65 \%$ of the building indoor air is remixed with the fresh outdoor air which may reduce the indoor air quality. The driving force behind this mixing is the reduction of energy cost through the reduction of cooling and heating loads. Enhancing indoor air quality could be achieved by using 100\% of fresh and clean outdoor air for the purpose of air conditioning inside buildings. However, this comes at a high energy cost when using conventional heating, ventilating and air-conditioning (HVAC) systems. In contrast, energy recovery from the exhausted air to the supplied fresh air offers an adequate option to current industrial applications [1].

Membrane heat exchangers are currently one of the corner stones of energy recovery solutions in use for HVAC systems [2-4]. The membrane is simply a thin film material that comes in different forms: a normal paper or an engineered porous material. Figure 1 shows the structure of the membrane heat exchanger and how energy is recovered within the heat exchanger. Simply, heat and moisture are transferred from the hot/humid side to the membrane surface via convection. Then, heat crosses the membrane via conduction and moisture diffuses through the porous membrane. Finally, the transported heat and moisture are transferred to the cold/less humid stream side. This process results in producing cooler and less humid air supplied to the cooling coil without consuming additional energy.

The moisture resistance of a thin film membrane depends on the inlet air humidity [5-13] and it affects the transported amounts of moisture across the membrane. In low humidity climate, inlet conditions might not affect significantly the variation in moisture transportation. However, highly humid inlet air conditions could affect the estimation of moisture transported quantities, performance of the heat exchanger and amount of energy recovered. Liang et al. [14] reported that under hot and humid conditions, an air conditioning system coupled with cross flow membrane heat exchanger could improve the system performance significantly when compared with $100 \%$ fresh air supplied conventional HVAC system.

Computational fluid dynamics (CFD) approach has been widely used in modelling energy transfer within heat exchangers [15-19]. Heat and moisture transfer processes could be simulated efficiently using CFD approach [20, 21]. Using CFD as a tool contributes strongly to estimating the effectiveness of the heat exchanger and to developing ways to enhance its performance. Therefore, modelling complex geometries of heat exchanger such as the utilized Z-shape configuration became possible. 
Min and $\mathrm{Su}$ [7, 22-24] derived a set of mathematical equations to analyze heat and mass transfer across a membrane-based enthalpy exchanger. They initially used vapor density difference as the moisture transfer driving force. Then, they modified their approach by utilizing the humidity ratio difference as the driving force. They concluded that the thermal conductivity of the membrane has an insignificant influence on all forms of effectiveness: sensible, latent, and total.

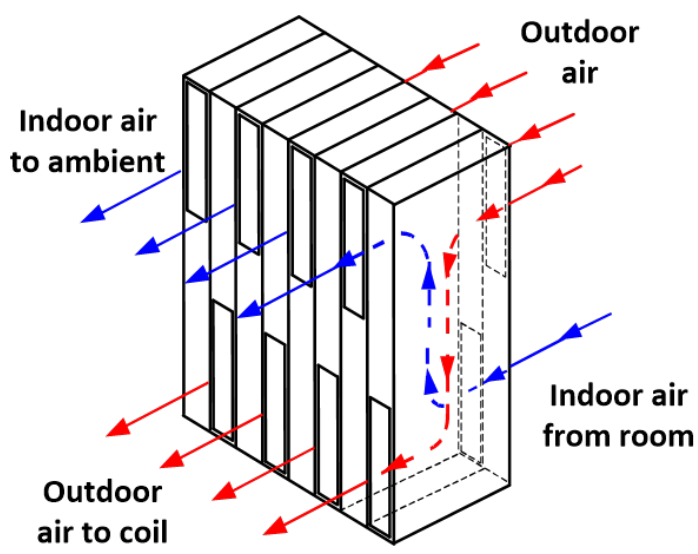

(a)

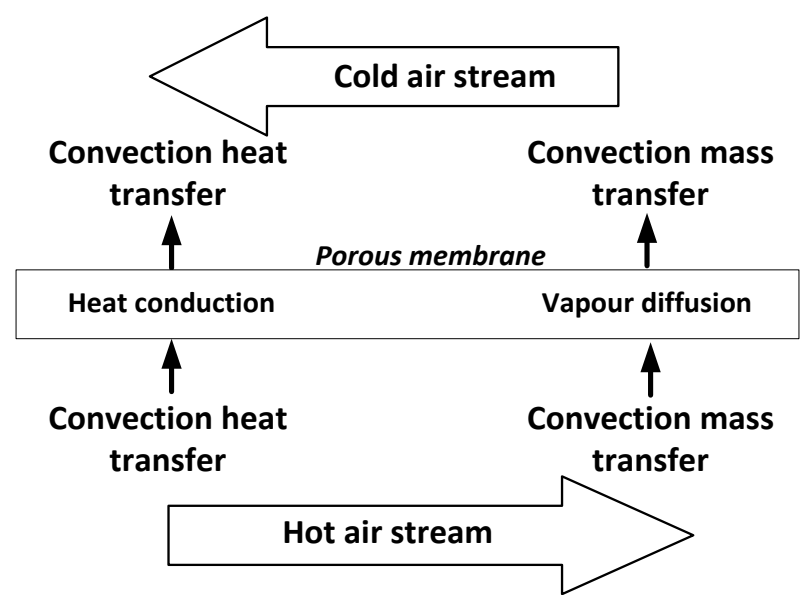

(b)

Figure 1. (a) Modelled Z-shape configuration heat exchanger (b) Energy recovery mechanisms across the thin film membrane

Yaïci et al. [18] investigated the performance of heat and energy recovery ventilators using CFD approach. Laminar heat and mass transfer processes were modelled under Canadian summer and winter conditions. Two heat exchangers with different configurations were modelled: counter-flow and parallel-flow. They reported that outdoor conditions had minor effects on the simulated heat exchanger performance. Moreover, they stressed that CFD is an efficient design tool that could assist in designing and manufacturing energy recovery systems under different flow configurations, operating conditions and material properties.
Zhang et al. [10-13, 19, 25] produced a detailed and comprehensive work on membrane heat exchangers. They investigated different types of membrane materials at different operating conditions. They conducted experimental and numerical experiments of a simple square membrane heat exchanger. They reported the fact that counter flow configuration produces the highest heat/mass transfer efficiency. However, this configuration is very difficult to adopt in a full-scale installed air conditioning system. Therefore, there is a need for a heat exchanger with a different configuration to overcome this real life problem. Consequently, they developed a quasi-counter flow membrane-based total heat exchanger that has both cross and counter flow configurations with an easy to install layout.

Al-Waked et al. [1, 8, 9, 15, 16, 26, 27] performed detailed investigations on modelling and simulating heat and moisture transfer across porous membranes inside a Z-shape and other configurations heat exchangers. They simulated heat and moisture transfer across both constant and variable resistance membranes. Their work was validated against experimental results produced in their full scale test laboratory. In their energy recovery work, they reported that an air conditioning system coupled with an enthalpy heat exchanger consumed $8 \%$ less energy throughout the year and emitted $900 \mathrm{~kg} /$ year of $\mathrm{CO}_{2}$ less when compared with conventional air conditioning system installed in a tropical climate.

The current work builds on the comprehensive work of other researchers. It presents a CFD study of heat and moisture transfer within a Z-shape thin-film membrane heat exchanger. An in-house user defined function (UDF) has been developed to be integrated within FLUENT [28]. The UDF dictates how moisture is transferred across different thin film membrane materials: 45 gsm [4], 60 gsm Kraft paper [4], modified cellulose acetate membrane [12] and PVA/LiCl blend membrane [19]. Effects of ambient air conditions on the performance of the heat exchanger have been studied, too.

\section{Materials and Methods}

Two channels on both sides of the membrane were modeled in the current CFD study. One flow channel for the hot stream and another for the adjacent cold stream. Due to similarity conditions, one half of each of the flow channels was modelled as shown by Figure 2. The height of the simulated channel was $3 \mathrm{~mm}$. The other related dimensions of the membrane heat exchangers adopted in this investigation are shown by Figure 2. The membrane materials have the same properties as those reported by other publications, listed in Table 1: 45 gsm Kraft paper (K45) [4] and 60 gsm Kraft paper (K60) [4], modified cellulose acetate membrane (MCA) [12] and PVA/LiCl blend membrane (PLB) [19]. 


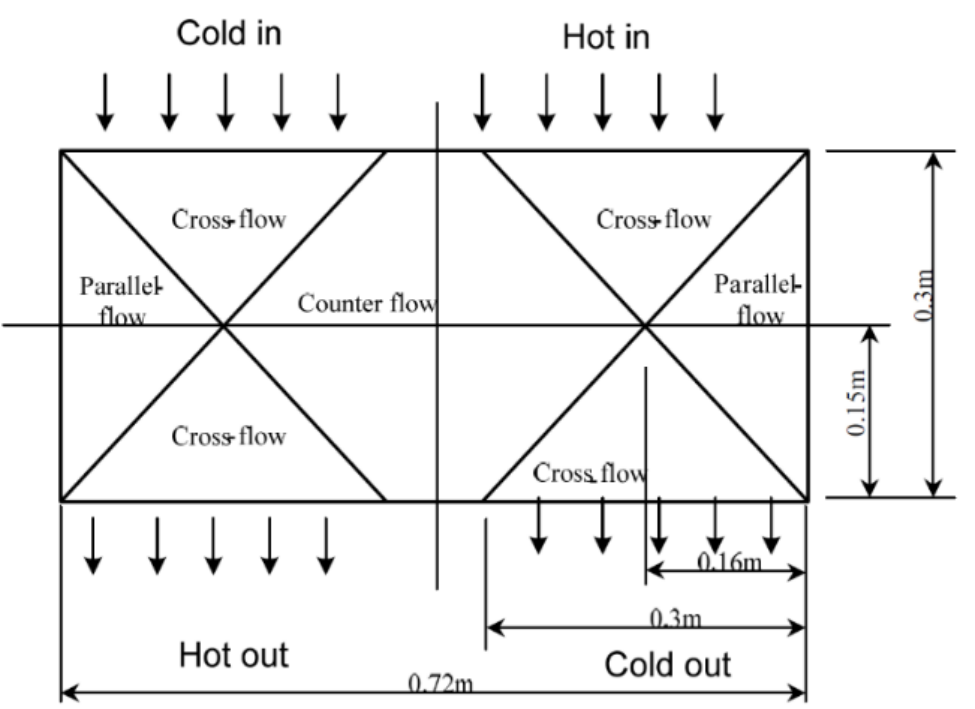

(Top view)

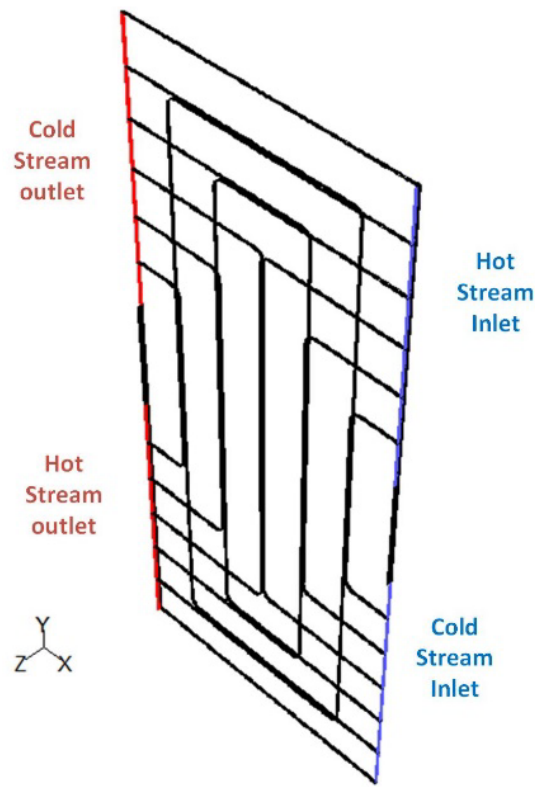

(Isometric view)

Figure 2. Simulated heat exchanger flow arrangement with dimensions [4]

Table 1. Reference values of the simulated membranes

\begin{tabular}{|l|c|c|c|c|}
\hline \multicolumn{1}{|c|}{ Membrane } & K45 [4] & K60 [4] & MCA [12] & PLB [19] \\
\hline Thickness, $\delta(\mu \mathrm{m})$ & 78 & 98 & 5 & 102 \\
\hline Moisture transfer resistance $\left(\mathrm{R}_{60 \mathrm{gsm}}\right)\left(\mathrm{m}^{2} . \mathrm{s} / \mathrm{kg}\right)$ & $95868 \Delta \omega+42.6$ & $84988 \Delta \omega+38.388$ & & \\
\hline Porosity & 0.0027 & 0.0029 & & \\
\hline Thermal conductivity $(\mathrm{W} / \mathrm{m} . \mathrm{K})$ & 0.12 & 0.12 & 0.41 & 0.13 \\
\hline Heat capacity $(\mathrm{J} / \mathrm{kg} . \mathrm{K})$ & 871 & 871 & & 773 \\
\hline Density $\left(\mathrm{kg} / \mathrm{m}^{3}\right)$ & 578 & 613 & $1.12 \times 10^{-11}$ & $8 \times 10^{-6}$ \\
\hline Membrane diffusion coefficient $\left(\mathrm{m}^{2} / \mathrm{s}\right)$ & & & 2.5 & \\
\hline Maximum sorption uptake $\left(\mathrm{W}_{\max }\right)$ & & & 8.64 & \\
\hline Constant in sorption curve $(\mathrm{C})$ & & & & \\
\hline
\end{tabular}


The CFD simulations were based on the steady state model of the pressure based solver. The heat exchanger was modeled as a three dimensional numerical domain. Moisture transfer within the model was simulated using the volumetric species transport model. Calculations of pressure and velocity fields were conducted based on semi implicit method for pressure linked equation (SIMPLE) algorithm. Furthermore, the third order MUSCAL discretization scheme was used with momentum, energy, and species equations and the second order upwind discretization scheme was used with the pressure model.

\subsection{Governing Equations}

Equations that govern the incompressible air flow within the heat exchanger are presented in this section. The continuity equation (1), the energy equation (2) and the species equation (3) all were modelled and solved by FLUENT [28].

$$
\begin{gathered}
\nabla \cdot(\rho \phi \overrightarrow{\mathrm{V}})=\nabla \cdot\left(\Gamma_{\phi} \nabla \phi\right)+\mathrm{S}_{\phi} \\
\nabla \cdot(\overrightarrow{\mathrm{V}}(\rho \mathrm{E}+\mathrm{p}))=\nabla \cdot\left(\mathrm{k} \nabla \mathrm{T}-\sum_{\mathrm{i}} \mathrm{h}_{\mathrm{i}} \overrightarrow{\mathrm{J}}_{\mathrm{i}}\right) \\
\nabla \cdot\left(\rho \overrightarrow{\mathrm{V}} \mathrm{Y}_{\mathrm{i}}\right)=\nabla \cdot \overrightarrow{\mathrm{J}}_{\mathrm{i}} \\
\overrightarrow{\mathrm{J}}_{\mathrm{i}}=-\rho \mathrm{D}_{\mathrm{i}, \mathrm{ma}} \nabla \mathrm{Y}_{\mathrm{i}} \\
\mathrm{D}_{\mathrm{a}, \mathrm{ma}}=\mathrm{D}_{\mathrm{v}, \mathrm{ma}}=1.87 \times 10^{-10} \frac{\mathrm{T}^{2.072}}{\mathrm{P}}
\end{gathered}
$$

where $\mathrm{k}$ is the thermal conductivity, $\mathrm{T}$ is the moist air temperature and $\mathrm{J}_{\mathrm{i}}$ is the diffusion flux of species " $\mathrm{i}$ ". Energy transfer due to conduction and species diffusion are represented by right hand side of equation (2). Mass fraction of air or moisture controls the diffusion flux as defined by equation (4). Furthermore, the diffusion coefficient $\left(\mathrm{D}_{\mathrm{i}, \mathrm{ma}}\right)$ of air or moisture within the air mixture is defined by equation (5).

\subsection{Membrane Modelling}

The simulated thin film membrane was modeled as a solid wall boundary. Equations of heat and mass transfer processes at the thin film membrane surfaces are represented by equation (6) - equation (10). In the current CFD model, the amount of heat transferred across the membrane is estimated by the coupled mechanism provide by FLUENT. However, the developed UDF dictates on how moisture is transferred across the membrane based on equation (9) and equation (10) and solves related equations resulted from Fick's law [29]. The adopted effectiveness of the thin film membrane heat exchanger are: sensible $\left(\varepsilon_{\mathrm{s}}\right)$, latent $\left(\varepsilon_{\mathrm{l}}\right)$ and total $\left(\varepsilon_{\mathrm{t}}\right)$ effectiveness, based on equation (11) - equation (13) [4]. The thermal energy recovered (TER) was calculated based on equation (14).

$$
\begin{gathered}
\frac{\partial^{2} \mathrm{~T}_{\mathrm{m}}}{\partial \mathrm{z}^{2}}=\frac{\partial^{2} \mathrm{Y}_{\mathrm{i}, \mathrm{m}}}{\partial \mathrm{z}^{2}}=0 \\
\mathrm{q}_{\mathrm{h}}=-\left.\mathrm{k} \frac{\partial \mathrm{T}}{\partial \mathrm{z}}\right|_{\mathrm{hs}}=-\left.\mathrm{k}_{\mathrm{m}} \frac{\partial \mathrm{T}_{\mathrm{m}}}{\partial \mathrm{z}}\right|_{\mathrm{m}}=-\left.\mathrm{k} \frac{\partial \mathrm{T}}{\partial \mathrm{z}}\right|_{\mathrm{cs}} \\
\mathrm{j}_{\mathrm{v}}=-\left.\rho \mathrm{D}_{\mathrm{v}, \mathrm{ma}} \frac{\partial \mathrm{Y}_{\mathrm{v}}}{\partial \mathrm{z}}\right|_{\mathrm{hs}}=-\left.\rho \mathrm{D}_{\mathrm{m}} \frac{\partial \mathrm{Y}_{\mathrm{v}, \mathrm{m}}}{\partial \mathrm{z}}\right|_{\mathrm{m}}=-\left.\rho \mathrm{D}_{\mathrm{v}, \mathrm{ma}} \frac{\partial \mathrm{Y}_{\mathrm{v}}}{\partial \mathrm{z}}\right|_{\mathrm{cs}} \\
\mathrm{Y}_{\mathrm{v}, \mathrm{mc}}=\mathrm{Y}_{\mathrm{v}, \mathrm{cs}}+\mathrm{a}_{1} \mathrm{Y}_{\mathrm{v}, \mathrm{hs}}-\mathrm{a}_{1} \mathrm{Y}_{\mathrm{v}, \mathrm{mh}} \\
\mathrm{Y}_{\mathrm{v}, \mathrm{mh}}=\frac{\frac{\rho_{\mathrm{h}}}{\rho_{\mathrm{v}, \mathrm{cs}}}+\left(\mathrm{a}_{1} \frac{\rho_{\mathrm{c}}}{\rho_{\mathrm{h}}}+\mathrm{b}_{1}\right) \mathrm{Y}_{\mathrm{v}, \mathrm{hs}}}{\left(\mathrm{a}_{1} \frac{\rho_{\mathrm{c}}}{\rho_{\mathrm{h}}}+\mathrm{b}_{1}+1.0\right)} \\
\varepsilon_{\mathrm{s}}=\frac{\dot{\mathrm{m}}_{\mathrm{h}} \mathrm{c}_{\mathrm{p}}\left(\mathrm{T}_{\mathrm{hi}}-\mathrm{T}_{\mathrm{ho}}\right)+\dot{\mathrm{m}}_{\mathrm{c}} \mathrm{c}_{\mathrm{p}}\left(\mathrm{T}_{\mathrm{co}}-\mathrm{T}_{\mathrm{ci}}\right)}{2 \dot{\mathrm{m}}_{\min } \mathrm{c}_{\mathrm{p}}\left(\mathrm{T}_{\mathrm{hi}}-\mathrm{T}_{\mathrm{ci}}\right)} \\
\varepsilon_{1}=\frac{\dot{\mathrm{m}}_{\mathrm{h}} \mathrm{h}_{\mathrm{fg}}\left(\omega_{\mathrm{hi}}-\omega_{\mathrm{ho}}\right)+\dot{\mathrm{m}}_{\mathrm{c}} \mathrm{h}_{\mathrm{fg}}\left(\omega_{\mathrm{co}}-\omega_{\mathrm{ci}}\right)}{2 \dot{\mathrm{m}}_{\min } \mathrm{h}_{\mathrm{fg}}\left(\omega_{\mathrm{hi}}-\omega_{\mathrm{ci}}\right)} \\
\varepsilon_{\mathrm{t}}=\frac{\dot{\mathrm{m}}_{\mathrm{h}}\left(\mathrm{H}_{\mathrm{hi}}-\mathrm{H}_{\mathrm{ho}}\right)+\dot{\mathrm{m}}_{\mathrm{c}}\left(\mathrm{H}_{\mathrm{co}}-\mathrm{H}_{\mathrm{ci}}\right)}{2 \dot{\mathrm{m}}_{\min }\left(\mathrm{H}_{\mathrm{hi}}-\mathrm{H}_{\mathrm{ci}}\right)} \\
\mathrm{TER}=\dot{\mathrm{m}}_{\mathrm{h}}\left(\mathrm{H}_{\mathrm{hi}}-\mathrm{H}_{\mathrm{ho}}\right)
\end{gathered}
$$

\section{Results and Discussion}

In this section, results of moist airflow simulation inside the Z-shape heat exchanger are presented and discussed. Moreover, the volumetric flow rate through the simulated channels were maintained constant for all simulated cases.

\subsection{Validation}

Validation of the current CFD model has been reported in earlier works $[1,15,16]$ for different membrane materials and heat exchanger configurations. In this section, mesh dependency analysis is reported and a validation case of the K45 membrane is discussed. The K45 membrane was experimentally tested by Nasif [4] to show the effect of flow velocity on the thermal performance of the Z-shape heat exchanger. The investigated experimental ambient conditions are listed in Table 2 at different flow velocities through the heat exchanger. The current CFD code worked on reproducing the experimental work of Nasif [4] and the result of this comparison is shown by Figure 3 . 
Table 2. Reference experimental values of K45 membrane used for the validation of the CFD model [4]

\begin{tabular}{|c|c|c|c|c|}
\hline & \multicolumn{2}{|c|}{ Hot Inlet } & \multicolumn{2}{c|}{ Cold Inlet } \\
\hline Velocity $(\mathrm{m} / \mathrm{s})$ & Dry Bulb Temperature $\left({ }^{\circ} \mathrm{C}\right)$ & Mass Fraction $\left(\mathrm{kg}_{\mathrm{v}} / \mathrm{kg}\right)$ & Dry Bulb Temperature $\left({ }^{\circ} \mathrm{C}\right)$ & Mass Fraction $\left(\mathrm{kg}_{\mathrm{v}} / \mathrm{kg}\right)$ \\
\hline 3.6 & 308.35 & 0.01204 & 294.15 & 0.00780 \\
\hline 5.8 & 303.15 & 0.01084 & 293.85 & 0.00848 \\
\hline 7.2 & 301.05 & 0.00920 & 292.65 & 0.00705 \\
\hline 7.9 & 302.15 & 0.00983 & 293.15 & 0.00762 \\
\hline
\end{tabular}

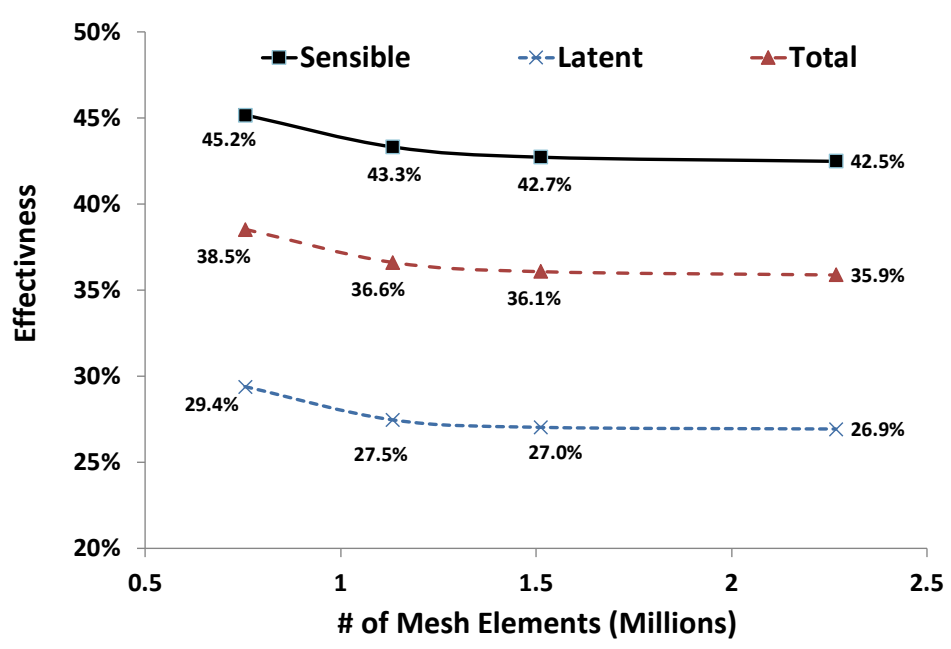

(a)

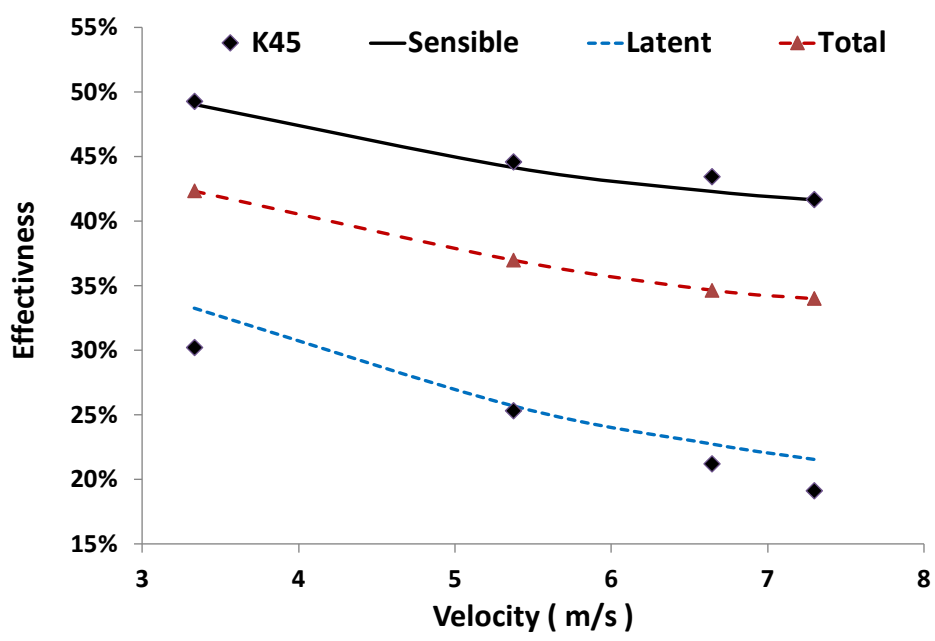

(b)

Figure 3. Validation of the Z-shape heat exchanger (a) Mesh sensitivity for K45 membrane at $5 \mathrm{~m} / \mathrm{s}$; (b) comparison with experimental data [4]

Mesh sensitivity analysis was conducted to examine the dependency of the CFD model on the number of mesh elements. The flow inside the heat exchanger was assumed to be turbulent as a result of the high air velocity of $5 \mathrm{~m} / \mathrm{s}(\mathrm{Re}=3800)$. The Standard $\mathrm{k}-\varepsilon$ model was adopted with the enhanced wall treatment function at the walls. The cold air conditions were: $21^{\circ} \mathrm{C}$ dry-bulb temperature and a mass fraction of $0.0078 \mathrm{~kg}_{\mathrm{v}} / \mathrm{kg}$. Moreover, the outdoor hot air conditions were: $35.2^{\circ} \mathrm{C}$ dry-bulb temperature and a mass fraction of $0.012 \mathrm{~kg}_{\mathrm{v}} / \mathrm{kg}$. Four different sizes of mesh element were examined ranging from 0.7 to 2.3 million elements. Based on Figure $3 a$, it can be seen that a difference of $3 \%$ between high and low effectiveness values resulted from the difference in mesh element sizes with big sizes (low number of elements) resulting in higher effectiveness. It was also noticed that the difference in effectiveness dropped to lower than $0.2 \%$ at mesh elements number greater than 1.5 million. Therefore, it is safe to assume that a mesh independent solution was achieved at the total number of mesh elements of 1.5 million. This conclusion was carried on to investigate the effect of air velocity inside the 
Z-shaped heat exchanger on the thermal effectiveness and to compare these results with the reported results of Nasif [4] as shown by Figure 3b.

Results of the CFD simulations shown by Figure $3 \mathrm{~b}$ are based on the air conditions at the inlets of the heat exchanger listed in Table 2 . The presented experimental data were labeled as K45 with square dots in Figure 6b and the curves are the results of the CFD simulations. The CFD code predicted the sensible effectiveness with high accuracy and overestimated the latent effectiveness by a maximum difference of $3 \%$. The CFD code has a built in function that estimates the heat transfer across walls. Furthermore, it is well documented that the sensible effectiveness is independent of the thermal conductivity of the membrane. Both of these reasons have led to accurate prediction of the CFD simulations. On the other hand, the developed UDF estimated the mass transfer across the membrane which contributed to higher discrepancies in predicting the latent effectiveness. Nevertheless, the reported results could be considered accepted for validation purposes and the CFD code could be considered acceptable for further studies.

\subsection{Simulation Results}

The simulated thin film membranes were $45 \mathrm{gsm}$ Kraft paper (K45) [4], 60 gsm Kraft paper (K60) [4], modified cellulose acetate membrane (MCA) [12] and $\mathrm{PVA} / \mathrm{LiCl}$ blend membrane (PLB) [19]. All four membranes were simulated at same air speed of $5 \mathrm{~m} / \mathrm{s}$ and ambient conditions $[12,16]$. Fresh air at the inlet of the hot stream side was at $35^{\circ} \mathrm{C}$ dry bulb temperature and a relative humidity of $59 \%$. On the other hand, exhaust air conditions at the inlet of the cold stream side were: $27^{\circ} \mathrm{C}$ dry bulb temperature and a relative humidity of $54 \%$. The thermal performances of the simulated membranes at a speed of $5 \mathrm{~m} / \mathrm{s}$ are shown by Figure 4 .

As expected, all four membranes produced almost the same sensible effectiveness of $43 \%$ regardless of their physical properties such as thickness and porosity at the same simulated air conditions. This result has confirmed earlier works of sensible effectiveness insensitivity to the variation in the porous and/or nature of membranes in use $[7,22]$. This is confirmed by the temperature contours shown by Figure 5 for the K45 membrane.

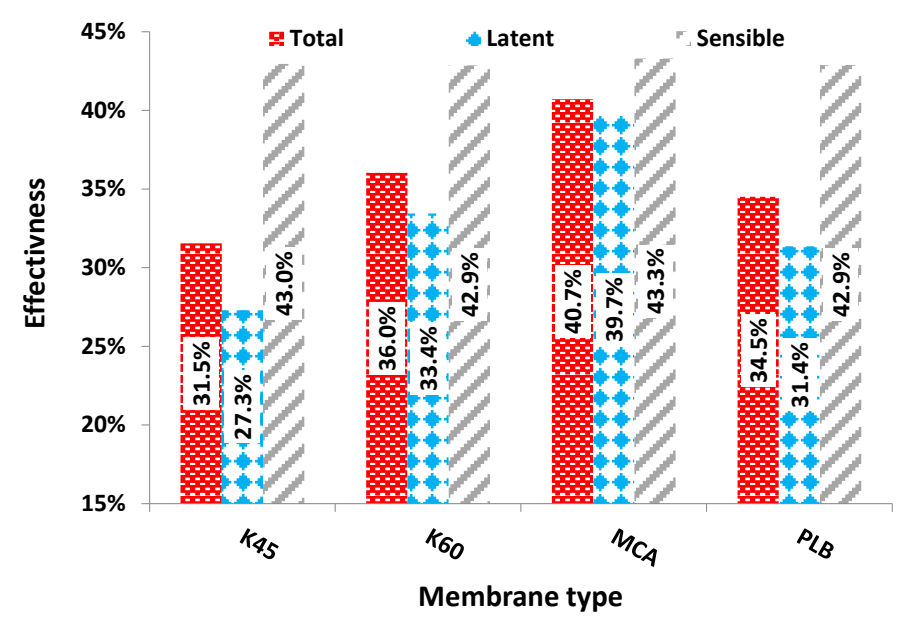

Figure 4. Effectiveness of simulated membranes at $5 \mathrm{~m} / \mathrm{s}$

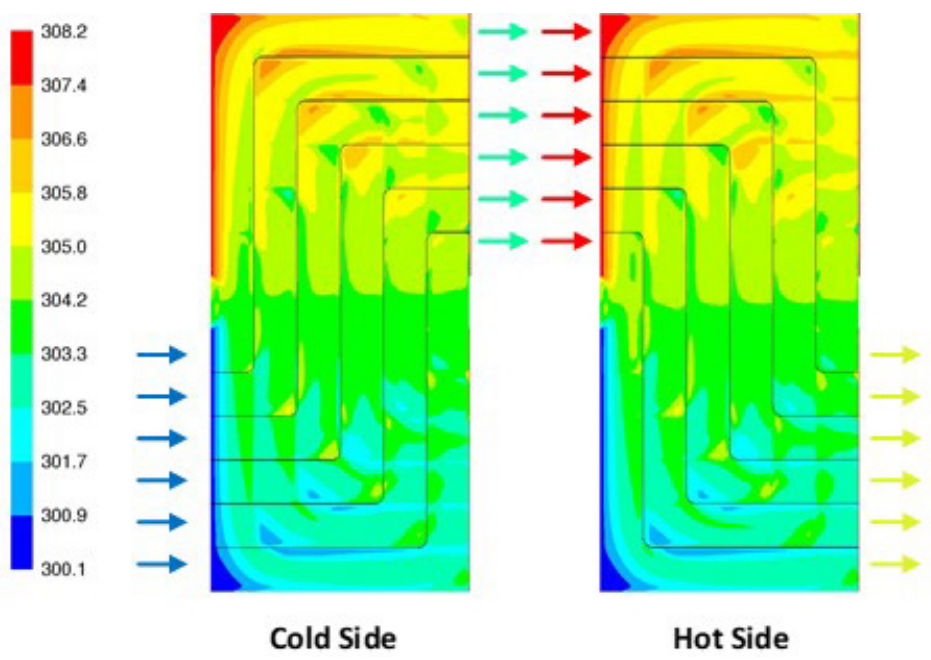

Figure 5. Temperature $(\mathrm{K})$ contours of $\mathrm{K} 45$ membrane's sides at $5 \mathrm{~m} / \mathrm{s}$ 
Figure 5 shows that the distribution of the contours on both sides of the membrane were almost the same. This means that the thermal resistance of the membrane does not play a major role in dictating the heat transfer process across the membrane. At the exit of the hot/cold streams, it could be noticed that the temperature is not equally distributed across all flow channels and not all flow channels have the same average temperature. This is due to the heat transfer configuration that each flow channel faced between the inlet and the exit. With reference to Figure 2, the best reported heat exchanger configuration is the counter flow configuration and the worst is the parallel flow configuration. Therefore, each channel exit temperature would have different value based on the percentages of the flow configuration faced whether it is counter, cross or parallel flow. It is worth mentioning that all of the four simulated membranes resulted in the same temperature contours layout and that why on K45 temperature contours were reported.

The latent effectiveness has showed higher sensitivity towards the variation in physical properties of simulated membranes as shown by Figure 6. Porosities of K45 or K60 membranes are not uniform or engineered with thicknesses of $78 \mu \mathrm{m}$ and $98 \mu \mathrm{m}$, respectively. However, the MCA and PLB membranes are engineered membranes, properties of these membranes are uniform and homogenous with thicknesses of $5 \mu \mathrm{m}$ and $102 \mu \mathrm{m}$, respectively. The MCA membrane showed the highest performance while the K45 membrane showed the lowest performance. The main advantage of the MCA membrane, from thermal performance point view, over other membranes was the minimal difference between the sensible and latent effectiveness. As it can be seen, from
Figure 4, the difference was less than $5 \%$ where it was higher than $10 \%$ for the other membranes. This is due to the membrane thickness, diffusivity and maximum moisture uptake $[4,12,16]$. The MCA membrane thickness is less than $7 \%$ of the thickness of other membranes. Therefore, moisture transfer resistance for MCA membrane is lower than other membranes which led to more moisture transfer across the membrane and consequently, higher latent effectiveness.

The mass fraction contours of both sides of the membrane shown by Figure 6 highlight the importance of the membrane moisture resistance. Differences between the $\mathrm{K} 45$ and the MCA membrane contours are obvious. The cold stream side of the K45 membrane has a majority of blue colored contours (average value of 0.01451 $\mathrm{kg}_{\mathrm{v}} / \mathrm{kg}$ ). This means low amount of moisture was transferred from the hot/humid stream due to the high moisture resistance of the membrane. The major color for the MCA cold side membrane was almost green (average value of $0.01559 \mathrm{~kg}_{\mathrm{v}} / \mathrm{kg}$ ). This mean high amount of moisture was transferred from the hot side due to the low moisture resistance. Same conclusions could be extracted for the hot sides of the membranes. The existence of circulation zones at the both sides of the membrane is clear in Figure 6. These zones came as a result of sudden change in flow direction and the resulted boundary layer separation. These zones reduce the thermal performance of the heat exchanger because they hinder the heat and/or moisture transfer processes. Exit conditions of mass fraction showed better uniformity in the distribution than the temperature case. This could be related to the utilized User Defined Function (UDF) that enhanced such uniformity $[15,16]$.

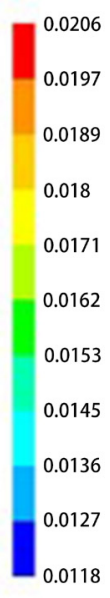

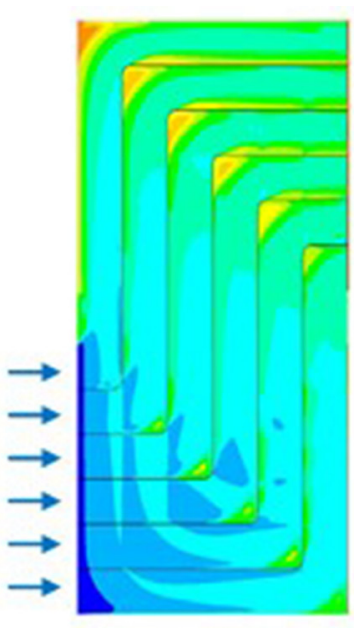

Cold Side

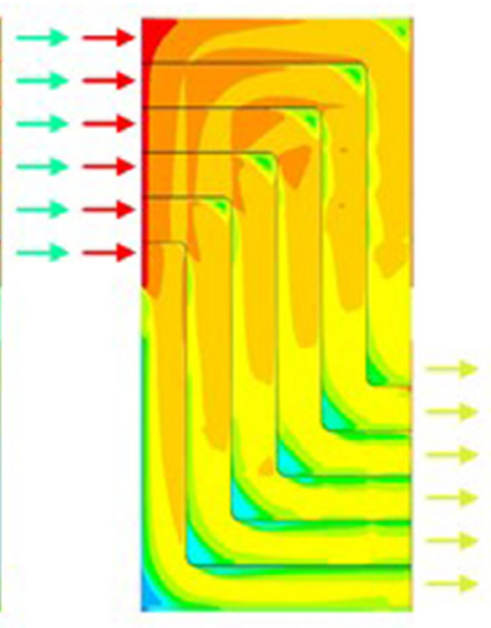

Hot Side

(K45 membrane) 

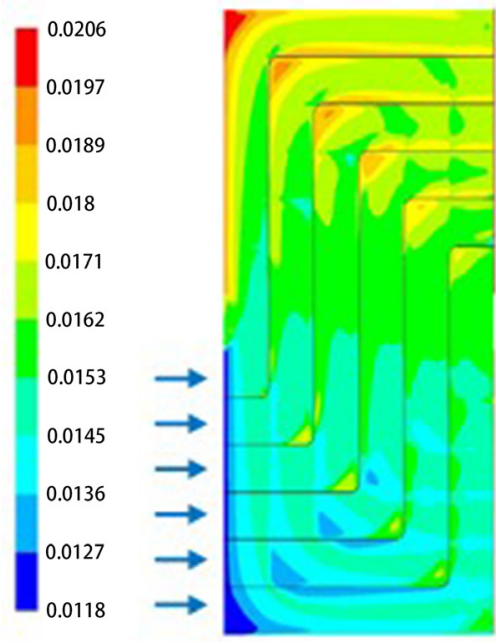

Cold Side

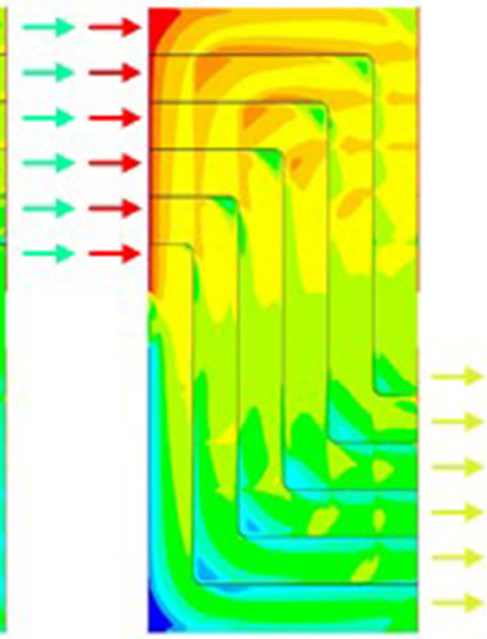

Hot Side

(MCA membrane)
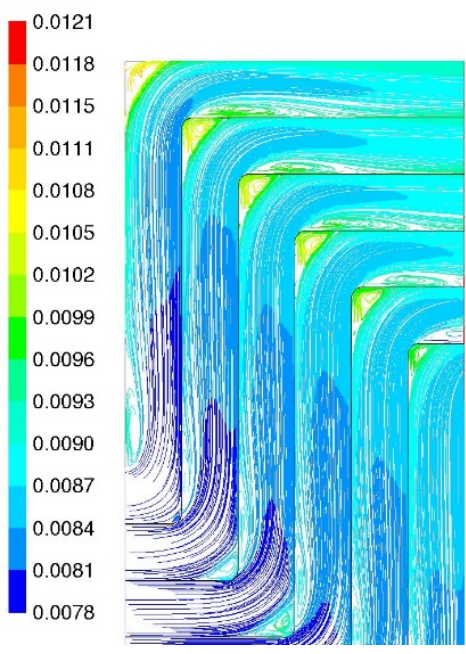

(cold side)

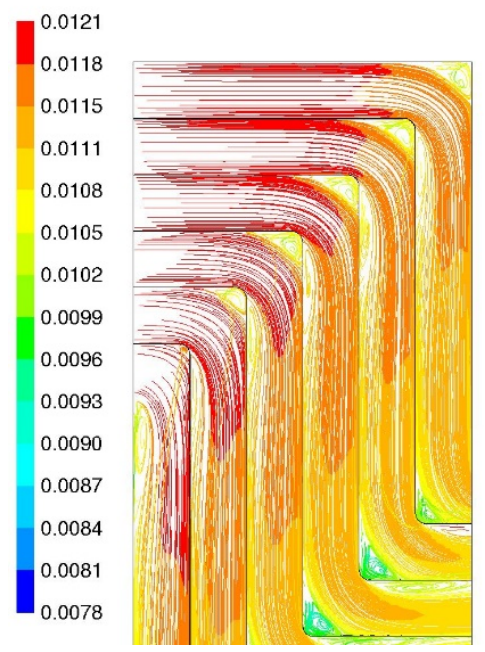

(hot side)

Figure 6. Mass fraction $\left(\mathrm{kg}_{\mathrm{v}} / \mathrm{kg}\right)$ contours and path lines of membrane's sides at $5 \mathrm{~m} / \mathrm{s}$

The amount of energy recovered from the simulated part of the heat exchanger has ranged from $100 \mathrm{~W}$ to 130 $\mathrm{W}$ as shown by Figure 7. This amount of energy is considered very high at the given flow speed of $5 \mathrm{~m} / \mathrm{s}$. The majority of the energy recovered was due to the moisture transfer from the humid side to the less humid side of the membrane. Energy recovered due to heat transfer process was relatively small and was less than $20 \%$ of total amount. The importance of porosity of the membrane on the total performance was evident as shown for K45 (porosity $=0.0027$ ) and $\mathrm{K} 60$ (porosity $=0.0029$ ) membranes [4]. The energy recovered from K45 membrane was $99 \mathrm{~W}$ whereas it was $113 \mathrm{~W}$ from the $\mathrm{K} 60$ membrane. As explained earlier, the MCA membrane produced the highest thermal performance which was reflected on the highest amount of energy recovered. As a result, the higher the thermal performance of the heat exchanger for a given membrane, the larger amount of energy recovery is to be expected.

Heat exchangers are installed at different parts of the world and expected to perform at different ambient conditions. Relative humidity $(\mathrm{RH})$ of air is the main factor that affect the performance of these heat exchangers. At flow speeds of $2.5 \mathrm{~m} / \mathrm{s}$ (low speed) and $7.2 \mathrm{~m} / \mathrm{s}$ (high speed) the MCA membrane was tested under variable RH and fixed conditions of the exhausted air from the building. As shown by Figure 8, the sensible effectiveness showed insensitivity toward variation in $\mathrm{RH}$, whereas, the latent effectiveness showed dependency on variation in RH. For the simulated range of $\mathrm{RH}$, the latent effectiveness has varied by $6 \%$ at air speed of $2.5 \mathrm{~m} / \mathrm{s}$ and by $12 \%$ at air speed of $7.2 \mathrm{~m} / \mathrm{s}$. It is clear that as RH increases, the thermal performance, also, increases. This is due to the increase in the driving force of the moisture 
transfer process across the membrane which is represented by differences in moisture mass fraction at both sides of the membrane. However, as the flow speed increases the difference between the sensible and the latent effectiveness increases. This is because the convection effect becomes very significant and because the moist air has less residence time to fulfil the moisture transfer process across the membrane Furthermore, as air speed increases inside the heat exchanger, the thermal performance (effectiveness) decreases $[15,16]$.

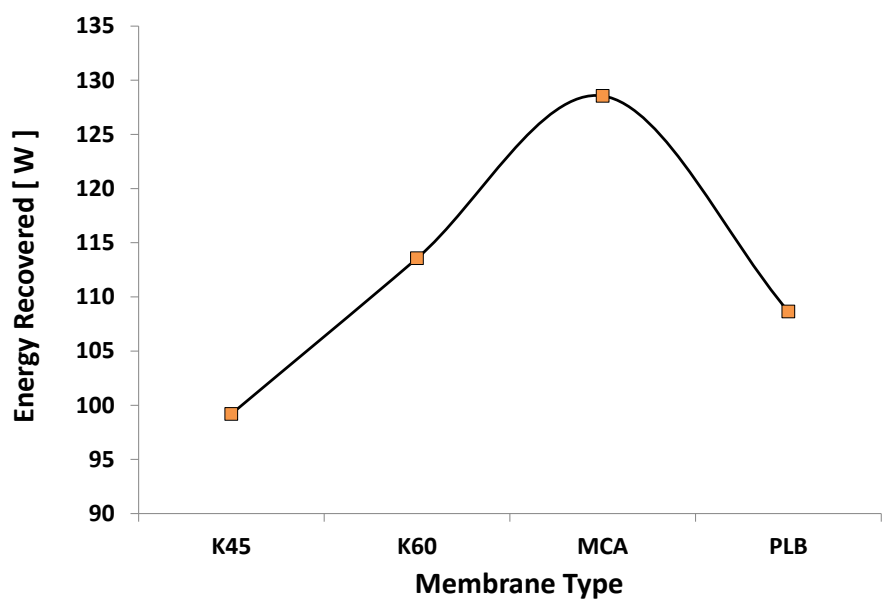

Figure 7. Thermal energy recovered in one channel at $5 \mathrm{~m} / \mathrm{s}$

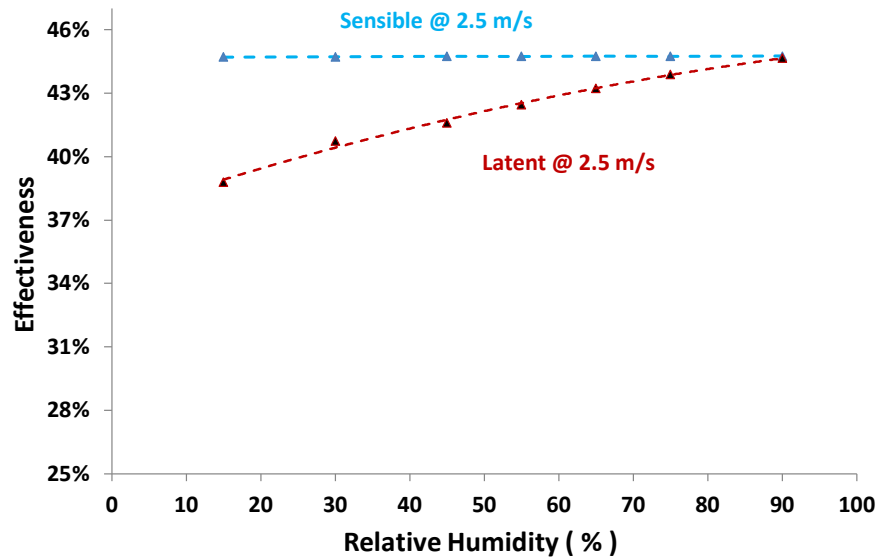

(Air speed $2.5 \mathrm{~m} / \mathrm{s}$ )

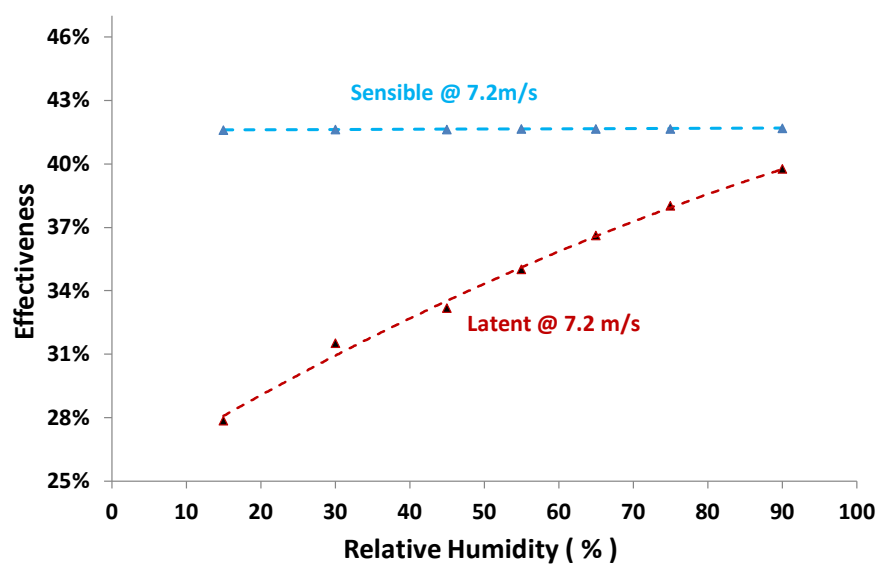

(Air speed $7.2 \mathrm{~m} / \mathrm{s}$ )

Figure 8. Performance of membrane heat exchanger at variable relative humidity 

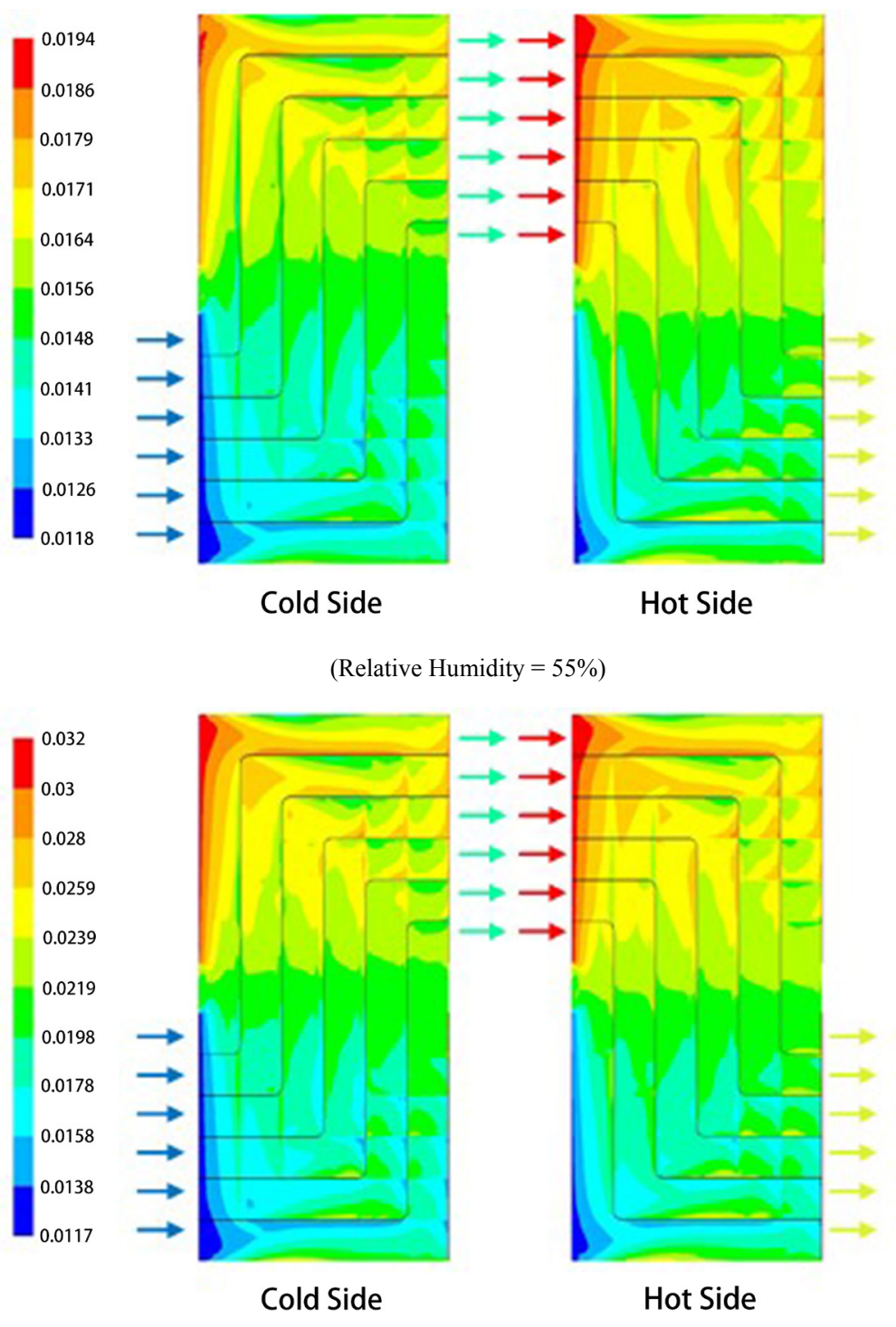

(Relative Humidity $=90 \%$ )

Figure 9. Mass fraction contours under variable relative humidity of MCA membrane at $2.5 \mathrm{~m} / \mathrm{s}$

The nature of heat and/or mass transfer process requires a driving force and a residence time to occur. The higher the driving force, the better the transfer process. As shown by Figure 8 - Figure 10, the driving force for heat transfer was kept constant. However, the driving force for moisture transfer was changed as a function of relative humidity. The higher the $\mathrm{RH}$, the greater the potential for moisture transfer from the hot/humid side towards the cold/less humid side. The maximum difference in mass fraction at $\mathrm{RH}=55 \%$, as shown by Figure 9, was equal to $0.0076 \mathrm{~kg}_{\mathrm{v}} / \mathrm{kg}$. However, this value changed to 0.0202 $\mathrm{kg}_{\mathrm{v}} / \mathrm{kg}$ at $\mathrm{RH}=90 \%$. Consequently, the amount of moisture transferred from the hot stream towards the cold stream is expected to be larger at higher humidity. However, these values averaged toward $0.016 \mathrm{~kg}_{\mathrm{v}} / \mathrm{kg}$ and $0.021 \mathrm{~kg}_{\mathrm{v}} / \mathrm{kg}$ at the middle height of the heat exchanger with green contours for both $\mathrm{RH}=55 \%$ and $90 \%$, respectively. 

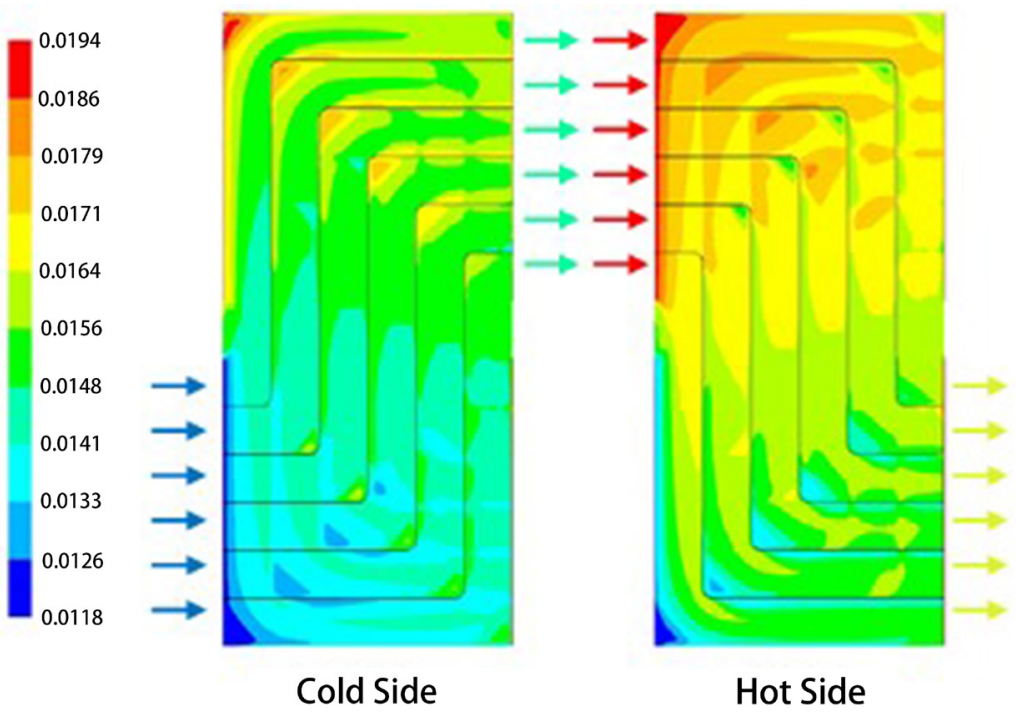

(Relative Humidity $=55 \%)$

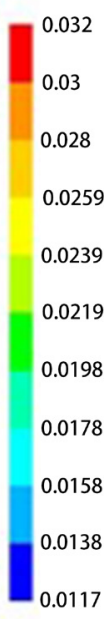

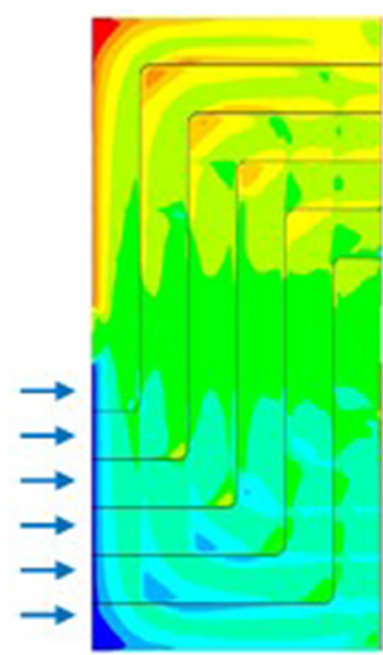

Cold Side

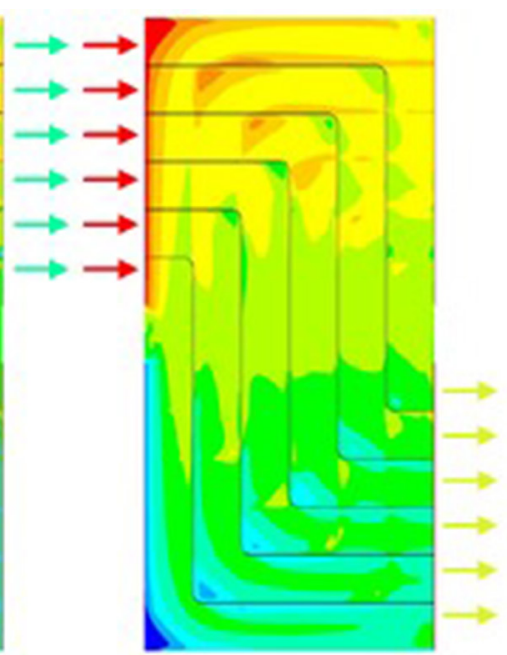

Hot Side

(Relative Humidity $=90 \%$ )

Figure 10. Mass fraction contours under variable relative humidity of MCA membrane at $7.2 \mathrm{~m} / \mathrm{s}$

The other main factor for a better moisture transfer process is the residence time of the air flow within the heat exchanger. Figure 10 shows the resulted contours of air flowing at a speed of $7.2 \mathrm{~m} / \mathrm{s}$ inside the MCA membrane heat exchanger. The time for the moisture to transfer from the hot side to the cold side needs to be less than the time required for the flow to enter and to exit the heat exchanger flow channel. As the flow speed increases, the residence time decreases. This results in lower potential for moisture to be carried by the flow on the other side of the membrane. Consequently, the thermal performance of the heat exchanger become lower than required. This is why laminar flow membrane heat exchanger is favored over turbulent flow ones.

\section{Conclusions}

Thermal performance of a thin film membrane heat exchanger using four different types of membrane materials has been investigated. The effect of ambient air relative humidity on the performance of the MCA membrane has also been investigated.

Results from CFD simulations at typical HVAC system conditions showed that the sensible effectiveness value remained constant at various flow speeds with a value of around $43 \%$. However, the latent effectiveness behaved differently and was sensitive to the flow speed and physical conditions where its value ranged between $27 \%$ and $31 \%$. Moreover, the total energy recovered from the heat exchanger ranged from $95 \mathrm{~W}$ to $130 \mathrm{~W}$. 
Based on the simulations of the MCA membrane under variable $\mathrm{RH}$ it has been found that as flow speeds increased differences between the two effectiveness increased. The effect of convection and residence time were the main factors in determining the variation in the performance of the membrane heat exchanger.

Among the four simulated membranes, the MCA membrane resulted in the best thermal performance with total effectiveness of $40.7 \%$ and potential energy recovery of $130 \mathrm{~W}$. However, the thickness of the MCA membrane is around $5 \mu \mathrm{m}$ which make it vulnerable to the side effect of being damaged. This fact promotes the K60 membranes to be a potential alternative with low cost and relatively high performance.

\section{Nomenclature}

C: Constant in sorption curve

Cp: Specific heat (J kg-1 K-1)

$\mathrm{Ch}$ : Channel height (m)

D: Diffusion Coefficient (m2 s-1)

E: Mechanical Energy (J kg-1)

E: Emission rate ( $\mathrm{kg} \mathrm{m}-2 \mathrm{~s}-1)$

$\mathrm{h}$ : Enthalpy (J kg-1)

H: Total Enthalpy (J kg-1)

hfg: Enthalpy of evaporation (J kg-1)

J: Diffusion flux (kg m-2)

k: Thermal conductivity (W m-1 K-1)

$\dot{m}$ Mass flow rate (kg s-1)

P: Pressure $(\mathrm{Pa})$

Pop Operating pressure $(\mathrm{Pa})$

qh: Sensible heat flux (W m-2)

$\mathrm{S} \phi$ : Source term

$\mathrm{T}$ : Temperature (K)

v: Velocity (m s-1)

$\mathrm{x}, \mathrm{y}, \mathrm{z}$ : Cartesian coordinates

Yi: Mass fraction of each species ( $\mathrm{kg} \mathrm{kg}-1)$

Greek letters

$\varepsilon$ : Effectiveness (\%)

$\Gamma \phi$ : Diffusion coefficient of variable quantity $\phi$

$\rho$ : Density (kg m-3)

$\phi$ :Variable quantity $(1, \mathrm{U}, \mathrm{V}, \mathrm{W}, \mathrm{T}, \mathrm{Yv})$

Subscripts

a: air c: cold

h: hot

i: inlet, species index (dry air or vapor)

1: latent

m: membrane

ma mixed air

o: outlet

s: stream

S: sensible

t: total

v: vapor

\section{Acknowledgements}

The support by the Deanship of Graduate Studies and Scientific Research of the German Jordanian University (GJU), Jordan are gratefully acknowledged.

\section{REFERENCES}

[1] Al-Waked R., Nasif M. S., and Bani Mostafa D., "Enhancing the performance of energy recovery ventilators," Energy Conversion and Management, vol. 171, pp. 196-210, 2018.

[2] Al-Rabghi O.M., and Akyurt M.M., "A survey of energy efficient strategies for effective air conditioning," Energy Conversion and Management, vol. 45, pp. 1643-1654, 2004, 2004.

[3] Mardiana-Idayu A., and Riffat S. B., "Review on heat recovery technologies for building applications," Renewable and Sustainable Energy Reviews, vol. 16, no. 2, pp. 1241-1255, 2012, 2012.

[4] Nasif M. S., "Analysis and Modelling of Membrane Heat Exchanger in HVAC Energy Recovery Systems," $\mathrm{PhD}$ thesis in Mechanical Engineering, University of New South Wales, Sydney, 2008.

[5] Liu J., Li W., Liu J. et al., "Efficiency of energy recovery ventilator with various weathers and its energy saving performance in a residential apartment," Energy and Buildings, vol. 42, pp. 43-49, 2010, 2010.

[6] Liu S., Riffat S., Zhao X. et al., "Impact of adsorbent finishing and absorbent filming on energy exchange efficiency of an air-to-air cellulose fiber heat \& mass exchanger," Building and Environment, vol. 44, no. 2009, pp. 1803-1809, 2009, 2009.

[7] Min J. C., and Su M., "Performance analysis of a membrane-based energy recovery ventilator: Effects of outdoor air state," Applied Thermal Engineering, vol. 31, pp. 4036-4043, 2011.

[8] Nasif M. S., Al-Waked R., Behnia M. et al., "Air to air 
enthalpy heat exchanger," Heat Transfer Engineering, vol. 33, no. 12, pp. 1010-1023, 2012.

[9] Nasif M. S., Al-Waked R., Morrison G. et al., "Membrane heat exchanger in HVAC energy recovery systems: systems energy analysis," Energy and Buildings, vol. 42, pp. 1833-1840, 2010.

[10] Niu J. L., and Zhang L. Z., "Membrane-based enthalpy exchanger: material considerations and clarification of moisture resistance," Journal of Membrane Science, vol. 189, pp. 179-191, 2001.

[11] Zhang L. Z., "Progress on heat and moisture recovery with membranes: From fundamentals to engineering applications," Energy Conversion and Management, vol. 63, pp. 173-195, 2012, 2012.

[12] Zhang L. Z., Liang C. H., and Pei L. X., "Heat and moisture transfer in application scale parallel-plates enthalpy exchangers with novel membrane materials," Journal of Membrane Science, vol. 325, no. 2008, pp. 672-682, 2008, 2008.

[13] Zhang L. Z., and Niu J. L., "Energy requirmets for conditioning fresh air and long-term savings with a membrane-based energy recovery ventilator in Hong Kong," Energy, vol. 26, pp. 119-135, 2001.

[14] Liang C. H., Zhang L. Z., and Pei L. X., "Independent air dehumidification with membrane-based total heat recovery: Modeling and experimental validation," International Journal of Refrigeration, vol. 33, pp. 398-408, 2010, 2010.

[15] Al-Waked R., Nasif M. S., Morrison G. et al., "CFD simulation of air to air enthalpy heat exchanger," Energy Conversion and Management, vol. 74 pp. 377 - 385, 2013.

[16] Al-Waked R., Nasif M. S., Morrison G. et al., "CFD simulation of air to air enthalpy heat exchanger: Variable membrane moisture resistance," Applied Thermal Engineering, vol. 84, no. 6, pp. 301 - 309, 2015.

[17] Teoh H. C., and Lai S. O., "Study of the Effect of Spacer Orientation and Shape in Membrane Feed Channel using CFD Modellin," Jurnal Teknologi vol. 70, no. 2, pp. 47-53 2014.

[18] Yaïci W., Ghorab M., and Entchev W., "Numerical analysis of heat and energy recovery ventilators performance based on CFD for detailed design," Applied Thermal Engineering, vol. 51, no. 1-2, pp. 770-780, March 2013, 2013.
[19] Zhang L.Z., "Heat and mass tansfer in a quasi-counterflow membrane-based total heat exchanger," International Journal of Heat and Mass Transfer, vol. 53, pp. 5478-5486, 2010 .

[20] Gholami A., Wahid M. A., Mohammed H. A. et al., "Investigation on heat transfer enhancement in a corrugated fin-andtube compact heat exchanger" Jurnal Teknologi, vol. 78, no. 10-2, pp. 7-13, 2016.

[21] Shin C. Y., and Mohd-Ghazali N., "CFD simulation of a plate heat exchanger with trapezoidal chevro," Jurnal Teknologi, vol. 78, no. 8-4, pp. 19-24, 2016.

[22] Min J. C., and Su M., "Performance analysis of a membrane-based enthalpy exchnager: Effects of the membrane properties on the exchnager performance," Journal of Membrane Science, vol. 348, pp. 376-382, 2010.

[23] Min J. C., and Wang L., "Coupled heat and mass transfer during moisture exchange across a membrane," Journal of Membrane Science, vol. 430, pp. 150-57, 1 March 2013, 2013.

[24] Min J. C., and Wang L. N., "Heat of adsorption and its effect on transmembrane heat transfer," Journal of Membrane Science, vol. 409-410, pp. 173-179, 2012, 2012.

[25] Zhang L. Z., and N. J. L., "Effectiveness correlations for heat and moisture transfer processes in an enthalpy exchanger with membrane cores," ASME Journal of Heat Transfer, vol. 124, pp. 922-929, 2002.

[26] Nasif M.S., and Al-Waked R., "Seasonal weather conditions effect on energy consumption and $\mathrm{CO}_{2}$ emission for air conditioning systems coupled with enthalpy energy recovery heat exchanger," APCBEE Procedia, vol. 10, pp. 42-48, 2014.

[27] Nasif M. S., Al-Waked R., Behnia M. et al., "Air to air fixed plate enthalpy heat exchanger, performance variation and energy analysis "Journal of Mechanical Science and Technology, vol. 27, no. 11, pp. 3541-3551, 2013.

[28] FLUENT Incorporated, FLUENT user's guide version 6.3, Lebanon, New Hampshire, USA, 2006.

[29] Cengel Y. A., Heat and mass transfer: A practical approach, Third ed., Singapor: McGraw-Hill, 2006. 